\title{
HOW VEGETATED FORESHORES AFFECT PROBABILITIES AND CONSEQUENCES OF DIKE FAILURE
}

\author{
Vincent Vuik, Delft University of Technology, V.Vuik@tudelft.nl \\ Sebastiaan N. Jonkman, Delft University of Technology, S.N.Jonkman@tudelft.nl
}

\section{INTRODUCTION}

Coastal ecosystems, such as salt marshes, mangrove forests and reefs, can contribute to flood risk reduction by surge attenuation, wave energy dissipation and erosion reduction (Temmerman et al. 2013). Such ecosystems can work stand-alone, but here we consider hybrid engineering solutions, where ecosystems are utilized as vegetated foreshores along engineered structures (Fig. 1).

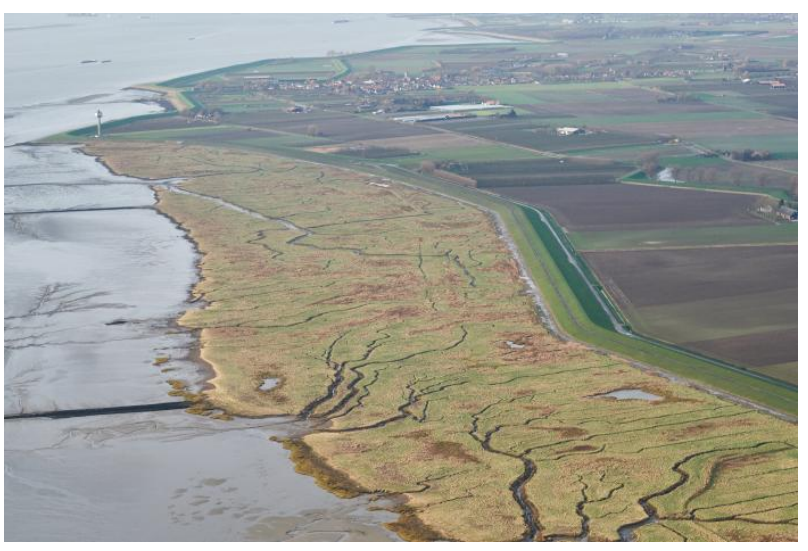

Figure 1 - Dike with vegetated foreshore in the Netherlands (Photo: Joop van Houdt / Rijkswaterstaat)

Flood risk in embanked areas is defined as the product of probability and consequences of dike failure. So far, no method is available to quantify the effect of a vegetated foreshore on the failure probability of a dike, and its effect on the consequences of dike breaching has been largely overlooked.

With state-of-the-art techniques, a failure probability and optimal design can be determined for a traditional dike, considering the stochastic behavior of load and strength. Uncertainties are even more relevant for more complex flood defense systems like hybrid engineering solutions, which combine ecological and engineering features. This study demonstrates how a failure probability can be computed for a configuration with dike and vegetated foreshore, taking uncertainties in load and strength of the system into account. The two most prevalent wavedriven failure mechanisms are considered: erosion of the crest and inner slope of the dike due to wave overtopping, and erosion of the revetment or grass cover on the outer slope due to the impact of breaking waves.

Further, we demonstrate how foreshores affected the breach growth process during historic catastrophic floods, thereby limiting the discharge of water into the embanked area and the subsequent consequences of dike breaching.

\section{METHODS}

A model framework (Fig. 2) is developed to compute the probability of failure of a dike with a vegetated foreshore.
This framework consists of the following components:

1. Boundary conditions (multivariate statistics of wind speed, water level, significant wave height, wave period);

2. A wave energy balance to compute wave transformation due to wave breaking, bottom friction and wave attenuation by vegetation (Vuik et al. 2018b);

3. A stem breakage model to compute the fraction of breaking stems due to wave-induced bending stresses (Vuik et al. 2018a);

4. A model to compute dike failure due to wave overtopping over the dike, or due to wave impact on the grass or asphalt revetment on the outer slope of the dike.

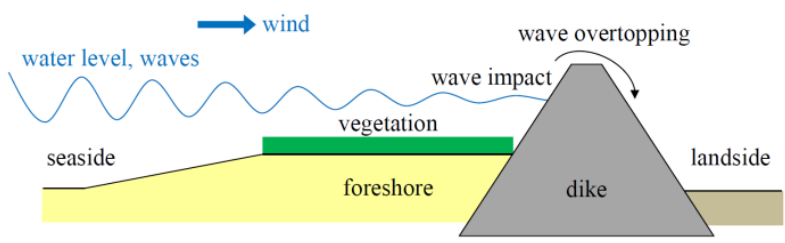

Figure 2 - Model framework with a dike and vegetated foreshore

Probability distributions and correlations between variables are defined for the boundary conditions, for variables that describe the foreshore, vegetation and dike characteristics, and for model parameters. Dike failure due to wave overtopping is described by the difference between the actual overtopping discharge (according to EurOtop, 2016) and the tolerable overtopping discharge which depends on the erosion resistance of the dike crest and rear slope. Failure of a grass cover on clay depends on the erosion rate and layer thickness, in comparison to the time duration in which the waves impact at a certain level on the dike. Failure of an asphalt revetment is a matter of fatigue. The critical number of load cycles that leads to dike failure depends on the magnitude of the wave impact and the characteristics of the asphalt and subgrade material. The actual number of load cycles follows from the storm duration and wave period.

The probabilistic method FORM is applied to compute the probability of failure for each of these three failure mechanisms, given the probability distributions of the relevant parameters.

\section{RESULTS}

Shallow foreshores lead to a reduction in wave height due to wave breaking. This may allow for a lower crest level (Fig. 3), or e.g., for application of a grass cover instead of an asphalt revetment, in order to obtain the same target probability of failure.

The additional contribution of wave attenuation by vegetation depends strongly on its stability under storm conditions. Many vegetation species will break during severe storms, and their effect reduces to drag by broken stems only (blue vs. green line in Fig. 3). 


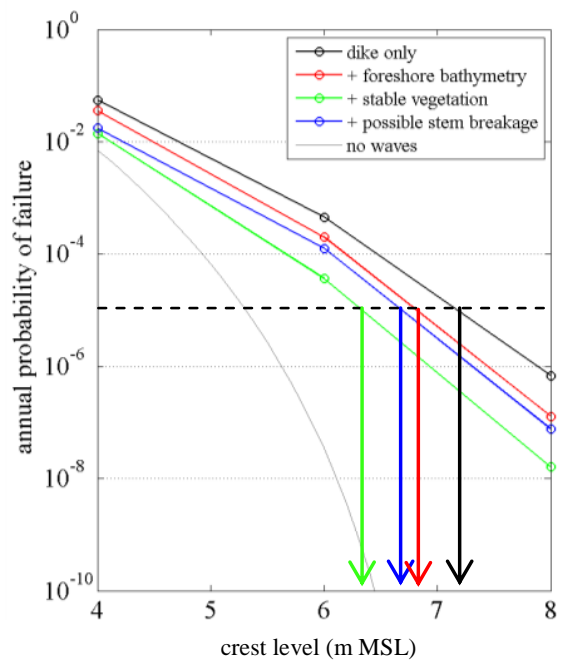

Figure 3 - Example of the relation between probability of failure due to overtopping and the dike crest level. Configurations: dike only (foreshore at $0 \mathrm{~m} \mathrm{MSL}$ ), dike with foreshore bathymetry only, or including stable or breakable vegetation. The arrows indicate the required crest level for the configurations, given a certain target failure probability.

The calculations show that vegetated foreshores reduce the probability of dike failure. Further, our analysis of historic catastrophic floods highlights that the presence of stable foreshores reduces the number of dike breaches and their dimensions (Fig. 4). Fewer and smaller dike breaches result in a smaller volume of water entering the flooded area, slower flood propagation, and a lower final inundation depth.

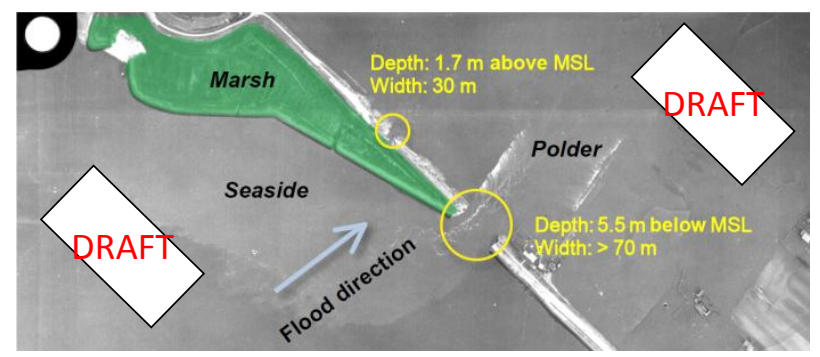

Figure 4 - Two dike breaches close to each other in the same dike, caused by the 1953 flood in the Netherlands: a small breach, constrained by the salt marsh in front of the dike, and a deep and wide breach in the part of the dike without stable foreshore (taken from Zhu et al., 2018).
The top layer of a salt marsh generally consists of stable, consolidated clay, reinforced with dense roots of the vegetation. This top layer will not erode due to the strong flow through the breach, and the original foreshore elevation confines the vertical breach growth process. The velocity of the critical flow through the breach depends on the upstream water depth on the foreshore. Therefore, also the flow velocity is limited by the presence of a foreshore. In contrast, a breach in a dike with a deep, erodible foreshore will quickly deepen and widen, which results in strong inflow, quickly rising inundation depth, and consequently, many casualties and much damage to property.

\section{CONCLUSIONS}

Vegetated foreshores in front of dikes can effectively reduce flood risk, (i) by reducing wave loads on the dike, and (ii) by reducing potential consequences of a flood due to confined breach dimensions.

\section{REFERENCES}

EurOtop (2016). EurOtop 2016: Manual on wave overtopping of sea defences and related structures. Van der Meer, J.W.; Allsop, N.W.H.; ... ; Zanuttigh, B.

Temmerman, S., Meire, P., Bouma, T.J., Herman, P.M.J., Ysebaert, T., De Vriend, H.J. (2013). Ecosystembased coastal defence in the face of global change. Nature, 504, 79-83.

Vuik, V., Suh Heo, H.Y., Zhu, Z., Borsje, B.W., Jonkman, S.N. (2018a). Stem breakage of salt marsh vegetation under wave forcing: $A$ field and model study. Estuarine, Coastal and Shelf Science, 200, 41-58.

Vuik, V., Van Vuren, S., Borsje, B.W., Van Wesenbeeck, B.K., Jonkman, S.N. (2018b). Assessing safety of Nature-based Flood Defenses: dealing with extremes and uncertainties. Coastal Engineering (in review).

Zhu, Z., Vuik, V., Soens, T., Visser, P.J., Van Wesenbeeck, B.K., Van de Koppel, J., Jonkman, S.N. (2018). Nature-based mitigation of coastal flood risks during historic and recent storms. (in review). 